\title{
The Processes of Lipoperoxidation and Antioxidant Protection in Men with Different Variants of Spermograms
}

\author{
N. A. Kurashova, PhD, ScD*; B. G. Dashiev; M. I. Dolgikh, PhD; L.I. Kolesnikova, PhD, ScD \\ Scientific Centre for Family Health and Human Reproduction Problems \\ Irkutsk, the Russian Federation
}

\begin{abstract}
Background: Currently, infertile couples represent a very complex and serious medical and social problem. In 40\%-60\% of cases, the reason for the absence of children in the family is the male factor. Oxidative stress (OS) has been identified as one of the many mediators of male infertility by causing sperm dysfunction. The purpose of this study was to identify the characteristics of the intensity indices of lipid peroxidation (LPO) and antioxidant system (AOS) in the ejaculate of men with different spermogram variants.

Materials and Methods: We performed a retrospective analysis of the results of examinations of 69 men of infertile couples with various disorders of the ejaculate and 155 healthy men with proven fertility. In the semen of the examined men, the level of CD (conjugated dienes), TBARS (thiobarbituric acid reactive substances), $\alpha$-tocopherol, retinol and total antioxidant activity (AOA) was evaluated by spectrophotometric method.

Results: We found that the antioxidant protection system in patients with asthenozoospermia was characterized by a decrease in the level of total AOA in the semen by $50 \%$ and the $\alpha$-tocopherol concentration by $52 \%$, compared to healthy men in the control group. In patients with oligozoospermia, an increase in the CD concentration by $39 \%$ and a decrease in the TBARS concentration by $26 \%$ was found; the level of total AOA decreased by $37 \%$ and the concentration of $\alpha$-tocopherol by $41 \%$, compared to healthy men.

Conclusion: In general, the analysis of the obtained data of the survey of men with different variants of spermograms indicates a change in the parameters of the LPO-AOS and confirms the OS development. Thus, it can be noted that depending on the pathological state of the ejaculate in men of reproductive age, LPO processes have their own characteristics, and in men with oligozoospermia, LPO processes occur more intensively. Activation of LPO-AOS processes can be both a consequence and a cause of various metabolic changes in the human body. (International Journal of Biomedicine. 2019;9(2):168-171.)
\end{abstract}

Key Words: men • sperm • lipid peroxidation • antioxidants

\section{Abbreviations}

AOA, antioxidant activity; AOS, antioxidant system; CD, conjugated dienes; ROS, reactive oxygen species; OS, oxidative stress; LPO, lipid peroxidation; TBARS, thiobarbituric acid reactive substances.

\section{Introduction}

Currently, infertile couples represent a very complex and serious medical and social problem..$^{(1-4)}$ Despite the improvement of clinical-laboratory examinations and methods, and the introduction of auxiliary reproductive technologies into the wide

*Corresponding author: Nadezhda A. Kurashova, PhD, ScD. Scientific Centre for Family Health and Human Reproduction Problems, Irkutsk, Russia. E-mail: nakurashova@yandex.ru clinical practice, the incidence of infertility in the marriage varies widely (7-28\%) and does not tend to decrease. ${ }^{(5)}$ In $40 \%-60 \%$ of cases, the reason for the absence of children in the family is the male factor. ${ }^{(4-7)}$ According to the literature, many factors affect the quality of the ejaculate, including an unfavorable ecological situation, inadequate and unbalanced nutrition, smoking, alcohol, inflammatory diseases of the genitourinary system, varicocele, and food products. ${ }^{(1,4)}$

OS has been identified as one of the many mediators of male infertility by causing sperm dysfunction. Active forms 
of oxygen (ROS) are necessary; under normal physiological conditions, they contribute to the reaction of capitation, regulation of maturation of spermatozoa and the development of cellular signaling pathways. Higher levels of ROS induce LPO, damage to sperm DNA and apoptosis. ${ }^{(8)}$ To overcome these undesirable consequences, ROS are naturally stabilized by the components of the body's antioxidant defense. In a healthy body, pro-oxidants and antioxidants remain in balance. However, under pathological conditions, the uncontrolled production of ROS exceeds the antioxidant capacity of the seminal plasma, resulting in OS. ${ }^{(1,9-12)}$ Spermatozoa are particularly vulnerable to OS because they do not have the necessary cytoplasmic antioxidant recovery systems. $20 \%-40 \%$ of infertile men have a higher level of ROS in the semen than in healthy men. ${ }^{(13)}$

Lipid composition of cell membranes of spermatozoa affects their functional characteristics. ${ }^{(14)}$ Long-chain polyunsaturated fatty acids in a high concentration are present in the male germ cells. Their number in relation to saturated fatty acids and cholesterol is closely related to the fluidity of the membranes of spermatozoa. ${ }^{(15)}$ Due to a significant number of double bonds, polyunsaturated fatty acids in the membranes of spermatozoa are particularly susceptible to LPO when there is an increase in the total amount of oxygen compounds formed and an imbalance in the components of the antioxidant system. In male infertility, the role of reactive oxygen species and decreased AOA in seminal plasma was established. ${ }^{(2,16)}$

The purpose of this study was to identify the characteristics of the intensity indices of LPO and AOS in the ejaculate of men with different spermogram variants.

\section{Materials and Methods}

We performed a retrospective analysis of the results of examinations of 69 men of infertile couples of Irkutsk city with various disorders of the ejaculate. All patients were divided into two groups: Group 1 included 45 men (mean age of $30.2 \pm 3.6$ years) with astenozoospermia; Group 2 included 24 men (mean age of $31.9 \pm 7.5$ ) with oligozoospermia. The control group consisted of 155 healthy men (mean age of $31.6 \pm 5.9$ years) with normozoospermia and a realized reproductive function.

Exclusion criteria were obesity, type 1 and type 2 diabetes, arterial hypertension, endocrine infertility, inflammatory diseases of the urogenital tract, including sexually transmitted infections.

The study was conducted in accordance with ethical principles of the Declaration of Helsinki (2000; revised October 2013, Fortaleza, Brazil). Written informed consent was obtained from all participants.

Methods of standard clinical examination of fertile and infertile men included: an ultrasonic scan of scrotum and prostate, macroscopic and microscopic examination of ejaculate, and biochemical analysis. The semen analysis was performed in accordance with the WHO recommendations. ${ }^{(17)}$

In the semen of the examined men, the content of $\mathrm{CD}$ (primary oxidation products) and TBARS, end products of LPO, was determined by the methods of V. Gavrilov et al. . $^{(18,19)}$ The level of $\alpha$-tocopherol and retinol was estimated by the method of R. Ch.Chernyauskene et al. ${ }^{(20)} \mathrm{AOA}$ according to GI Klebanov et al. ${ }^{(21)}$ The measurements were performed using a Shimadzu RF-1501 spectrofluorophotometer (Japan).

The statistical analysis was performed using the statistical software STATISTICA 6.1 (StatSoft Inc., USA). The mean (M) and standard deviation (SD) were calculated. For data with normal distribution, inter-group comparisons were performed using Student's t-test. A probability value of $P<0.05$ was considered statistically significant.

\section{Results and Discussion}

OS has been identified as one of the many mediators of male infertility. It is shown that in $30 \%-80 \%$ of cases of male infertility, pathospermia are caused by high levels of ROS in seminal plasma. ${ }^{(2,13,14)}$

We found that the antioxidant protection system in patients with asthenozoospermia was characterized by a decrease in the level of total AOA in the semen by $50 \%$ and the $\alpha$-tocopherol concentration by $52 \%$, compared to healthy men in the control group (Table 1).

\section{Table 1}

Parameters of the LPO-AOS system in healthy men (Control group) and in men with asthenozoospermia (Group 1)

\begin{tabular}{|l|c|c|c|}
\hline \multicolumn{1}{|c|}{ Parameter } & Control group & Group 1 & P-value \\
\hline $\mathrm{CD}(\mu \mathrm{mol} / \mathrm{l})$ & $1.27 \pm 0.81$ & $1.31 \pm 0.94$ & 0.791 \\
\hline TBARS $(\mu \mathrm{mol} / \mathrm{l})$ & $1.06 \pm 0.61$ & $0.89 \pm 0.46$ & 0.091 \\
\hline AOA (unit) & $3.86 \pm 2.26$ & $1.94 \pm 1.41$ & 0.000 \\
\hline$\alpha$-tocopherol $(\mu \mathrm{mol} / \mathrm{l})$ & $5.27 \pm 2.99$ & $2.53 \pm 1.90$ & 0.000 \\
\hline
\end{tabular}

As known, $\alpha$-tocopherol helps to preserve both sperm motility and morphology, protecting the components of sperm membranes from damage by OS. ${ }^{(22)}$ A number of studies have confirmed the positive effect of antioxidants on spermatogenesis disorders caused by OS. . $^{(3-25)}$

In patients with oligozoospermia (Table 2), we found an increase in the CD concentration by $39 \%$ and a decrease in the TBARS concentration by $26 \%$; the level of total AOA decreased by $37 \%$ and the concentration of $\alpha$-tocopherol by $41 \%$, compared to healthy men.

Table 2

Parameters of the LPO-AOS system in healthy men (Control group) and in men with oligozoospermia (Group 2)

\begin{tabular}{|l|c|c|c|}
\hline \multicolumn{1}{|c|}{ Parameter } & Control group & Group 2 & $P$-value \\
\hline CD $(\mu \mathrm{mol} / \mathrm{l})$ & $1.27 \pm 0.81$ & $1.77 \pm 0.73$ & 0.005 \\
\hline TBARS $(\mu \mathrm{mol} / 1)$ & $1.06 \pm 0.61$ & $0.78 \pm 0.29$ & 0.031 \\
\hline AOA (unit) & $3.86 \pm 2.26$ & $2.44 \pm 1.61$ & 0.003 \\
\hline$\alpha$-tocopherol $(\mu \mathrm{mol} / \mathrm{l})$ & $5.27 \pm 2.99$ & $3.14 \pm 2.10$ & 0.001 \\
\hline
\end{tabular}


The primary products of LPO, as a rule, are very unstable substances and are easily subjected to further transformations with the formation of more stable oxidation componentsaldehydes, ketones, low-molecular acids - as a result of which they exhibit a wide range of changes. A decrease in the level of TBARS in men with oligozoospermia may indicate activation of the enzymatic component of antioxidant protection, in particular SOD, and oxidized and reduced glutathione. ${ }^{(1,24,26)}$

Thus, the low level of total AOA and $\alpha$-tocopherol concentration in men with oligozoospermia and asthenozoospermia (Tabl. 1,2) indicates the activation of LPO process. Dramatic changes in cellular redox systems trigger the suppression of antioxidative defense in biological tissues and internal environments. Failure of antioxidant protection can lead to the following changes: damage to membranes, inactivation or transformation of enzymes, suppression of cell division, and accumulation of inert polymerization products in cells. ${ }^{(3)}$

Reduced sperm motility (asthenozoospermia) and low sperm count (oligozoospermia) are significant causes of male reproductive failure. Their origin is diverse and, in some cases, cannot be established. Reduced sperm motility can often be associated with ultrastructural flagellum disorders, which is a consequence of the genetic nature, as well as the result of external factors - adverse environment, smoking, alcohol, poor and micronutrient diet, sedentary lifestyle and much more. ${ }^{(27)}$ OS causes an arrest of spermatogenesis at the early meiotic stage and induces apoptosis, leading to oligozoospermia. ${ }^{(28)}$ Elevated ROS levels lead to the development of DNA mutations and damage to cell structures with the development of teratozoospermia. ${ }^{(7,28)}$ In preventing oxidative stress and reducing its negative impact on spermatogenesis, the simultaneous use of fat- and watersoluble vitamins is promising. ${ }^{(8)}$ In experiments to study the effects of $\alpha$-tocopherol, an increase in the mobility and functioning of sperm, and in the frequency of fertilization, was established. ${ }^{(29-31)}$

\section{Conclusion}

In general, the analysis of the obtained data of the survey of men with different variants of spermograms indicates a change in the parameters of the LPO-AOS and confirms the OS development. Thus, it can be noted that depending on the pathological state of the ejaculate in men of reproductive age, LPO processes have their own characteristics, and in men with oligozoospermia, LPO processes occur more intensively. Activation of LPO-AOS processes can be both a consequence and a cause of various metabolic changes in the human body. ${ }^{(32)}$

\section{Competing Interests}

The authors declare that they have no competing interests.

\section{References}

1. Kolesnikova LI, Kurashova NA, Bairova TA, Dolgikh MI, Ershova OA, Dashiev BG, et al.. Role of Glutathione-S-
Transferase Family Genes in Male Infertility. Bull Exp Biol Med. 2017;163(5):643-645. doi: 10.1007/s10517-017-3869-9. 2. Nikolaev AA, Loginov PV, Vetoshkin RV. [Participation of free radicals in the function of spermatozoa]. Astrakhan Medical Journal. 2014;(1):23-29. [Article in Russian].

3. Galimov SN, Akhmetov RM, Galimova EF, Bairamgulov FM, Bikkulova LR. [Molecular aspects of the impact of the Speroton complex on the male fertility in idiopathic infertility]. Urologiia. 2017;(2):88-92.[Article in Russian].

4. Shantanova LN, Osadchuk LV, Dashiev BG, Kleschev MA, Gutorova NV, Osadchuk AV, Bashelkhanov IS. [Assessment of reproductive health in young men of the Republic of Buryatia]. Bulletin of the East Siberian Scientific Center SB RAMS. 2012;88:44-46. [Article in Russian].

5. Artifeksova MS, Borodacheva IV, Sergeev MYu, Artiefeksov SB, Zhabin SG. [Indicators of life quality of the men from infertile couple]. Russian Journal of Human Reproduction. 2015;21(5): 84-88. [Article in Russian].

6. Moretti E, Collodel G, Fiaschi AI, Micheli L, Iacoponi F, Cerretani D. Nitric oxide, malondialdheyde and nonenzymatic antioxidants assessed in viable spermatozoa from selected infertile men. Reprod Biol. 2017;17(4):370-375. doi: 10.1016/j.repbio.2017.10.003.

7. Dorostghoal M, Kazeminejad SR, Shahbazian N, Pourmehdi M, Jabbari A. Oxidative stress status and sperm DNA fragmentation in fertile and infertile men. Andrologia. 2017;49(10). doi: 10.1111/and.12762. Epub 2017 Jan 26.

8. Khodos MYa, Kazakov YaE, Vidrevich MB, Brainina HZ. [Oxidative stress and its role in pathogenesis]. Journal of Ural Medical Academic Science. 2017;4(4):381-398. [Article in Russian].

9. Kolesnikova LI, Darenskaya MA, Kolesnikov SI. [Free radical oxidation: a pathophysiologist's view]. Bulletin of Siberian Medicine. 2017;16(4):16-29. [Article in Russian]. doi: 10.20538/1682-0363-2017-4-16-29.

10. Darenskaya MA, Kolesnikov SI, Rychkova LV, Grebenkina LA, Kolesnikova LI. Oxidative stress and antioxidant defense parameters in different diseases: ethnic aspects. Free Radical Biology \& Medicine. 2018;120(S1):S60. doi: 10.1016/j. freeradbiomed.2018.04.199.

11. Trussell JC. Optimal diagnosis and medical treatment of male infertility. Semin Reprod Med. 2013;31(4):235-6. doi: 10.1055/s-0033-1345269.

12. Henkel RR. Leukocytes and oxidative stress: dilemma for sperm function and male fertility. Asian $\mathrm{J}$ Androl. 2011;13(1):43-52. doi: 10.1038/aja.2010.76.

13. Lomteva SV, Savikina KG, Shestel AN, Sagamonova $\mathrm{KYu}$, Shkurat TP. Oxidative stress and male reproductive system. Valeology. 2015;(1):59-67. [Article in Russian].

14. Ploskonos MV. [Biochemical changes in the membrane of spermatozoa of fertile men under the influence of an inducer of oxidative stress and correction of these changes]. Russian Journal of Human Reproduction. 2015;(5):102-108 [Article in Russian].

15. Rudneva SA, Bragina EE, Arifulin EA, Sorokina TM, Shileiko LV, Ermolaeva SA, et al. [DNA fragmentation in spermatozoa and its relationship with impaired spermatogenesis]. Andrology and Genital Surgery. 2014;15(4):26-33. [Article in Russian].

16. Kurashova NA, Dolgikh MI, Ershova OA, Gavrilova OA, Osipova EV, Dashiev BG, et al. Associations of Polymorphic Variants of the Biotransformation Genes with the Components of the Glutathione System in Men with Infertility. International 
Journal of Biomedicine. 2017;7(3):226-230. doi: 10.21103/ Article7(3)_OA13.

17. WHOlaboratory manual for the examinationand processing of human semen - 5th ed. Available from: https://apps.who. int/iris/bitstream/handle/10665/44261/9789241547789_eng. pdf;jsessionid=46F8915182775DD661AE4D5247CDA $\overline{1} 62$ ? equence $=1$.

18. Gavrilov VB, Mishkorudnaya MI. [Spectrophotometric determination of the content of lipid hydroperoxes in the blood plasma]. Lab Delo. 1983;(3)33-36. [Article in Russian]. 19. Gavrilov VB, Gavrilova AR, Mazhul' LM. [Methods of determining lipid peroxidation products in the serum using a thiobarbituric acid test]. Vopr Med Khim. 1987;33(1):118-22. [Article in Russian].

20. Cherniauskene RCh, Varshkiavichene ZZ, Gribauskas PS. [Simultaneous fluorometric determination of the concentrations of vitamins $\mathrm{E}$ and $\mathrm{A}$ in blood serum]. Lab Delo. 1984;(6):362-5.[Article in Russian].

21. Klebanov GI, Babenkova IV, Teselkin IuO, Komarov OS, Vladimirov IuA. [Evaluation of the antioxidative activity of blood plasma using yolk lipoproteins]. Lab Delo. 1988;(5):5962. [Article in Russian]

22. Kolesnikova LI., Darenskaya MA, Rychkova LV, GrebenkinaLA,DolgikhMI, GavrilovaOA.EthnicPeculiarities of the Lipid Profile in Adolescent Representatives of Some Indigenous Ethnic Groups of Siberia. J Evol Biochem Phys. 2018;54(5):356-362. doi: 10.1134/S0022093018050034.

23. Kul'chenko NG. [Principal antioxidant therapy patospermia]. "REAVIZ" Bulletin: Rehabilitation, Doctor and Health. 2018;31(1):41-48. [Article in Russian].

24. Ahmadi S, Bashiri R, Ghadiri-Anari A, Nadjarzadeh A. Antioxidant supplements and semen parameters: An evidence based review. Int J Reprod Biomed. 2016;14(12):729-736.
25. Kolesnikova LI, Kurashova NA, Bairova TA, Osipova EV. Activity of components of lipid peroxidation system and antioxidant protection in men with infertility, carriers of non-functional genotypes GSTT1 and GSTM1. Free Radical Biology and Medicine. 2018;120(1):72-73. doi: 10.1016/j. freeradbiomed.2018.04.240

26. Kao SH, Chao HT, Chen HW, Huang Y-S, Liao TL, Wei $\mathrm{YH}$. Increase of oxidative stress in human sperm with lower motility. Fertil Steril. 2008;89(5),1183-90.

27. Madaeva IM, Berdina ON, Semenova NV, Madaev VV, Kolesnikova LI. Erectile dysfunction and sleep apnea syndrome are risk factors of cardiovascular diseases. European Journal of Preventive Cardiology. 2017; 24(S1): S288.

28. Walczak-Jedrzejowska R, Wolski JK, SlowikowskaHilczer J. The role of oxidative stress and antioxidants in male fertility. Cent European J Urol. 2013;66(1):60-67. doi: 10.5173/ceju.2013.01.art19

29. Belenkaia LV, Sholokhov LF, Kolesnikova LI. Levels of essential elements in pubic hair of men with type 1 diabetes. Endocrine Rev. 2017;38(S3):169-170.

30. Ammar O, Haouas Z, Hamouda B, Hamdi H, Hellara I, Jlali A, et al. Relationship between sperm DNA damage with sperm parameters, oxidative markers in teratozoospermic men. Eur J Obstet Gynecol Reprod Biol. 2019;233:70-75. doi: 10.1016/j.ejogrb.2018.12.003.

31. Intasqui $\mathrm{P}$, Antoniassi MP, Camargo M, Nichi $\mathrm{M}$, Carvalho VM, Cardozo KH, et al. Differences in the seminal plasma proteome are associated with oxidative stress levels in men with normal semen parameters. Fertil Steril. 2015;104(2):292-301. doi: 10.1016/j.fertnstert.2015.04.037. 32. Zagarskikh EIu, Labygina AV, Kurashova NA [Experience in the treatment of normogonadotropic infertility in men]. Urologiia. 2014;(5):87-9. [Article in Russian]. 